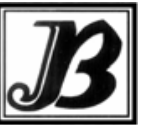

J. bio-sci. 18: 40-43, 2010

ISSN 1023-8654

http://www.banglajol.info/index.php/JBS/index

\title{
AGE-RELATED RESPONSE OF TRIBOLIUM CASTANEUM (HERBST) LARVAE TO DIATOMACEOUS EARTH AT DIFFERENT EXPOSURE PERIODS
}

\author{
Md Mosharrof Hossain, AMS Reza and Selina Parween* \\ Department of Zoology, University of Rajshahi, Rajshahi-6205, Bangladesh
}

\begin{abstract}
Context: Diatomaceous earth (DE) compounds have been recognized as reduced risk and eco-friendly compounds, which can be used in the insect pest management programmes for food storage and processing areas.

Objective: To determine the repellent or attractant property of a DE formulation (Mitex) against the larvae of Tribolium castaneum (Herbst), a major pest of stored-products.

Materials and Methods: The experiment was conducted in choice chambers, which was divided into two equal halves by drawing a line through the midline. One half of the chamber was loaded with untreated flour (control) and the other half was loaded with DE-treated flour. Twenty larvae of a definite age were released in the midline of the two foods, thus providing them an option for choosing either treated or untreated food. The experiment was set separately for different ages of larvae (9-, 12- and 15-day old), doses of DE $(2,4,8,16$ and $32 \mathrm{mg} D E / g$ of flour) and exposure periods (24-, 48-, 72-, 96- and 120-hours). All the experiments were replicated three times and conducted at $30 \pm 1^{\circ} \mathrm{C}$ in an incubator without humidity and light control. Differences of the distribution of the larvae in treated and untreated flour was analyzed by $\chi^{2}$ test.

Results: The efficacy of a diatomaceous earth (DE) compound (Mitex) as a repellent or an attractant was tested against 9-, 12- and 15-day old larvae of Tribolium castaneum (Herbst). Larvae of all ages were significantly $(p<0.001)$ repelled by DE at doses from 8-32 mg/g food at all exposure periods of 24-, 48-, 72- 96 and $120 \mathrm{~h}$. The mature larvae (15-day old) showed tolerance to the low doses like 2 and $4 \mathrm{mg} / \mathrm{g}$ food.

Conclusion: The present results revealed that DE can be used as a reduced risk repellent compound in the grain and cereal stores, flour mills and grocery shops to manage the larval population of $T$. castaneum.

Keywords: Age related response, T. castaneum, diatomaceous earth
\end{abstract}

\section{Introduction}

The management programmes for storage insect pests are in search of reduced risk compounds, which with high insecticidal potentials would be harmless to the environment and human health. In this regard diatomaceous earth (DE) show great potential in the Integrated Pest Management (IPM) programmes in grain and cereal stores (Korunic 1998). The DE compounds were safe for non-target organisms, but very much effective against the insect pests of agriculture and grain stores. The US Environmental Protection Agency allowed DE to be used in the food storage and processing area, and classified them as GRAS (Generally Recognized as Safe) as food additives (Anonymous 1991). DEs are also used in food stores in Australia (Bridgeman 1999).

DEs are soft rock produced from the fossil diatoms, finely ground and are commercialized as insecticides. These are non-toxic to mammals, but cause death to insects mainly due to desiccation and abrasion of the cuticle (Ebeling 1971, Rigaux et al. 2001, Arnaud et al. 2005). Published reports show that activity of the commercial DE formulations affect growth and development of different species of the stored-product insects, and provide long-term protection to the stored grains (Ulrichs et al. 2006). Cook (2003) proposed for using DEs to treat crevices and voids as a part of IPM strategy for flour mills. The present research aims at determining the repellent or attractant property of Mitex (a DE formulation) against the larvae of one of the major stored product pests, Tribolium castaneum (Herbst).

* Corresponding author E-mail: parween_s@yahoo.com 


\section{Materials and Methods}

Test materials: Larvae of the red flour beetle, $T$. castaneum were chosen for this experiment as a model insect to determine the attractant or repellent property of DE. Adult beetles were collected from the stock culture of reared on standard food (wheat flour : brewer's yeast, 19:1, (Park and Frank 1948) in the Entomology Laboratory, Department of Zoology, Rajshahi University. Sub-cultures were established by collecting freshly laid eggs. The sub-cultures were reared on standard food at $30 \pm 1 \mathrm{C}^{\circ}$ in an incubator without humidity and light control. The eggs hatched $3-4$ days after laying. The neonates were allowed to feed on the same food and the food was replaced by a fresh one after every three days (Mondal 1984). For this experiment the 9-, 12- and 15 day old larvae were used. Mitex, a commercial product containing DE, marketed by Agril, UK, was used. The experimental doses of Mitex used were 2, 4, 8, 16 and $32 \mathrm{mg}^{-9} \mathrm{of}^{-}$ standard food.

Experimentation: The experiment was conducted in choice chamber as described by Mathlein (1967), Mondal (1984) and Parweeen (1996). The choice chamber was made from a glass petridish (9 cm diameter). The petridish was divided into two equal halves by drawing a line across the middle. By the use of partition one half of the choice chamber was loaded with flour (untreated control) and the other half with treated (DE) flour. Twenty larvae of a definite age were released in the midline of the choice chamber, thus providing an option for the insects to select either treated or control food (Parween 1996). The experiments were set separately for each age of larva, each dose of DE and each exposure period (24, 48, 72, 96 and $120 \mathrm{~h}$ ). The choice chambers were kept undisturbed at room temperature in the laboratory. After each exposure period, both treated and untreated portions of food were poured separately on separate paper sheets. Then each of the treated and untreated flour was passed through a $500 \mu \mathrm{m}$ mesh sieve. The number of larvae found on the sieve was counted separately for both treated and untreated foods. The experiment was replicated three times. The number of beetles found in each food section was counted and the percentage was calculated from the average number of three replications. The differences of distribution of beetles on either food section were measured by $\chi^{2}$ tests for the level of significance.

\section{Results}

Response of 9-day old larvae: The data showed that 9-day old larvae of $T$. castaneum were repelled by DEtreated food at all dose levels at each exposure periods (Fig. 1a). At 24- $\mathrm{h}$ exposure, the dose from 8-32mg/g repelled $93.33 \%$ larvae $\left(\chi^{2}\right.$ value $\left.37.57, p<0.001\right)$. At $48 \mathrm{~h}$ exposure, $100 \%$ of 9 -day old larvae were repelled by the doses of 8 and $32 \mathrm{mg} / \mathrm{g}$ (Fig. 1a). Significantly higher percentage of 9-day old larvae showed avoidance to the DE-treated food at doses from 4 - $32 \mathrm{mg} / \mathrm{g}$ (Fig. 1a) at $72 \mathrm{~h}$ exposure. More than $90 \%$ nine day old larvae were repelled by DE at doses over $2 \mathrm{mg} / \mathrm{g}$ at 96 - and $120 \mathrm{~h}$ exposures (Fig.1a).

Response of 12-day old larvae: The 12 day old larvae showed similar response to DE treated food like 9 day old larvae at all exposure periods ( $p<0.001$ ) (Fig. 1b). At 24-h exposure $>90 \%$ larvae avoided the treated food at doses from $8-32 \mathrm{mg} / \mathrm{g}$, whereas the same level of response was found at doses $4-32 \mathrm{mg} / \mathrm{g}$ at 48 and $72 \mathrm{~h}$ exposures. The effect of DE was reduced with the increase of exposure time. More than $90-100 \%$ larvae were repelled by 8 - $32 \mathrm{mg} / \mathrm{g}$ at $96 \mathrm{~h}$ exposure, and by 16 and $32 \mathrm{mg} / \mathrm{g}$ at 120 day exposures.

Response of 15-day old larvae: The larvae of $T$. castaneum ignored 2 and $4 \mathrm{mg} / \mathrm{g}$ treated food, or otherwise avoided the treated food at doses from $8-32 \mathrm{mg} / \mathrm{g}$ (Fig.1c). At $24 \mathrm{~h}$ exposure, 15 day old larvae were repelled at all doses of DE except $2 \mathrm{mg} / \mathrm{g}$; but $>90 \%$ larvae showed avoidance to $8-32 \mathrm{mg} / \mathrm{g}$ of treated food. The same aged larvae were equally distributed in untreated and treated foods at 2 and $4 \mathrm{mg} / \mathrm{g}$, at 48 to120 $\mathrm{h}$ exposures. Ignorance to the DE-treated food by the 15 day old larvae was increased with the increase of exposure period but in general, the 15 day old larvae were significantly repelled by $D E$. 

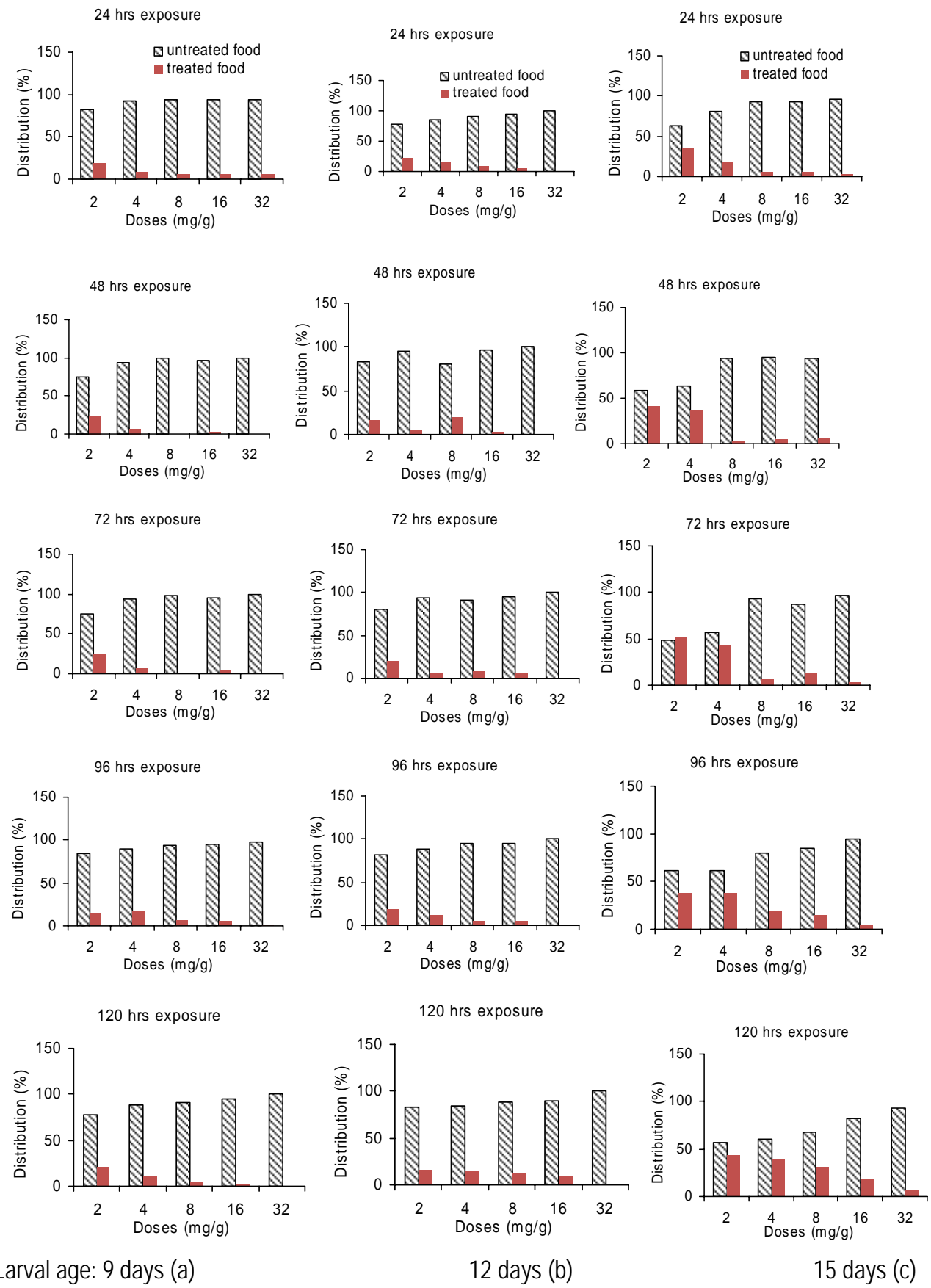

Larval age: 9 days (a)

12 days (b)

15 days $(\mathrm{c})$

Fig. 1. Distribution of different ages of larvae of $T$. castaneum on DE treated food at different periods. 


\section{Discussion}

Results of the experiment revealed that Mitex significantly $(p<0.001)$ repelled the larvae of all ages when exposed for 24 to $120 \mathrm{~h}$ by doses of 8,16 and $32 \mathrm{mg} / \mathrm{g}$. However, the young larvae (9 day old) were highly repelled by DE at doses as low as 2 and $4 \mathrm{mg} / \mathrm{g}$. The older larvae ( 15 day old) were repelled by the higher doses of DE compared to the younger ones.

Most of the published data on DE efficacy against the stored product insects have been reported on the toxicity of DEs, but not on the repellent or attractant properties of these compounds. According to Carlson and Ball (1962), Oryzaephilus mercator is more susceptible to DE than $T$. confusum, because the hairy cuticle of the former species is able to pick up more DE particles than Tribolium. Adult Rhizopertha dominica and $T$. castaneum have been reported to be tolerant to DE (Subramanyum and Roseli 2000), whereas, starved Sitophilus spp. are more susceptible to DE compared to those who were reared on food (Chiu 1939). Potentiality of DEs is related to the storage factors as well as metabolic conditions of the insect pests.

\section{Conclusion}

The present results revealed that $\mathrm{DE}$ can be used as a reduced risk repellent compound in the grain and cereal stores, flour mills and grocery shops to manage the larval population of $T$. castaneum.

\section{References}

Anonymous. 1991. EPA R.E.D. FACTS: Silicon-dioxide and Silica gel: 21T-1021, 1- 4 September, 1991.

Arnaud L, Lan HTT, Brostaux Y. Haubruge E. 2005. Effeicacy of DE formulations admixed with grain against populations of Tribolium castaneum. J Stored Prod Res 41,121-130. http://dx.doi:10.1016/j.jspr.2003.09.004

Bridgeman BW. 1999. Application technology and usage patterns of diatomaceous earth in stored product protection. In. J Zuxun, L Quan, L Yonsheng, T Xianchang, G Lianghua eds. Proc. $7^{\text {th }}$ Int Workg Conf Stored Prod Prot China, V1, 785-789.

Carlson SD, Ball HJ. 1962. Mode of action and insecticidal value of a diatomaceous earth as a grain protectant. J Econ Entomol 55(6), 964-970.

Chiu SF. 1939. Toxicity studies of so-called 'inert' materials with the rice weevil and the granary weevil. J Econ Entomol 32(1), 810-821.

Cook DA. 2003. The efficacy of high temperature and diatomaceous earth combinations against the adults of the red flour beetle Tibolium castaneum (Coleoptera: Tenebrionidae) and the grain weevil Sitophilus granarius (Coleoptera: Curculionidae). Proc. BCPC Int. Cong. Crop Sci. \& Technol. 10-12 November, 2003, Glasgow, UK, V1,445-450.

Ebeling W. 1971. Sorptive dusts for pest control. Annu Rev Entomol 16,123-158. http://dx.doi:10.1146/annurev.en.16.010171.001011 PMid:4324088

Korunic Z. 1998. Diatomaceous earths, a group of natural insecticides. J Stored Prod Res 34, 87-97. http://dx.doi:10.1016/S0022474X(97)00039-8

Mathlein R. 1967. Repellents tested against stored-product beetle pests. Contr Nat Ins Plant Prot Stockholm 13,112-447.

Mondal KAMSH. 1984. Effects of methylquinone, aggregation pheromone and pirimiphos-methyl on Tribolium castaneum Herbst larvae. PhD thesis, University of Newcastle upon Tyne, UK. 259pp.

Park T, Frank MB. 1948. The fecundity and development of the flour beetles, Tribolium confusum and Tribolium castaneum at three constant temperatures. Ecology 29, 368-375. http://dx.doi:10.2307/1930996

Parween S. 1996. The effect of triflumuron on malathion-susceptible (FSS II) and malathion-resistant (CTC 12) strains of Tribolium castaneum Herbst. PhD thesis, University of Newcastle upon Tyne, UK. 229pp.

Rigaux M, Haubruge E, Fields PG. 2001. Mechanisms for tolerance to DE between strains of Tribolium castaneum. Entomol Exp Appl 101, 33-39. http://dx.doi:10.1046/j.1570-7458.2001.00888.x

Subramanyam Bh, Roseli R. 2000. Inert dusts. In: Bh Sburamanyam, DW Hagstrum eds. Alternatives to Pesticides in Stored Product IPM, pp. 312-380. Kluwer Academic Publisher, Dordrecht, The Netherland.

Ullrichs C, Entenmann S, Goswami A, Mewls I. (2006) Abraassive and hydrophilic/lipophilic effects of different inert dusts used as insecticides against the stored product insect pest Sitophilus granarius L. Gesunde Pflanzen 58(3), 173-181. 